\title{
CORRESPONDENCE
}

\section{History of mesothelioma}

\section{To the Editor:}

McDonald and McDonald [1] present a version of the history of mesothelioma that for the sake of scholarship requires amendment. The references to the growth of knowledge of an association between mesothelioma and asbestos exposure are at variance with plain reading of the publications they cited. For example, GLOYNE [2] stated that he considered it worthwhile recording his two cases of squamous carcinoma of the lung occurring in asbestosis, "...not in any attempt to make out a case for an aetiological association of these two diseases, but in order to emphasize certain histological points in which one disease appears to bear upon the other". In each case the malignant lesion was very small, appeared to rise in the wall of a small bronchus and was not recognized in life. Nowhere is the question of mesothelioma referred to.

The authors interpret CARTIER [3] as giving his opinion that "...two such rare cancers in a small series of only eight cases suggested an occupational origin...". It is easy to misunderstand this, as the text is unclear. CARTIER [3] was concerned to discount asbestos as a cause of bronchogenic carcinoma, and not to make a case for mesothelioma being occupationally determined. The conference rapporteur reported him as saying: "...it seems obvious that many points would need discussion before anyone will be able to establish a causal relationship between these pathological findings and the asbestos factor. Is it not more logical to think that the same causal factor will produce the same type of tumour, and therefore, why do we observe such a variety of malignant tumours? If for a moment we may assume that the asbestos fibres might produce a bronchogenic carcinoma in asbestos employees with significant exposure, then only two cases (bronchial carcinoma) of the series would serve as evidence because the cases of mesothelioma or lymphosarcoma and cases without exposure or without asbestosis do not have the conditions required". CARTIER [3] listed two workers as having died of pleural mesothelioma, one having worked for $28 \mathrm{yrs}$ in the industry and having had no exposure to asbestos and no asbestosis, and the other having worked for 26 yrs in industry, including 10 yrs of exposure to asbestos, and with minimal asbestosis.

The authors refer to a paper by WeDLER [4] as describing two cases of pleural mesothelioma in 1943: apart from these two from his personal experience, he also provided accounts of other unpublished cases of mesothelioma in asbestos workers communicated to him, dating back to 1938. By 1943, German physicians were convinced that asbestos dust exposure was a cause of respiratory malignancies (they did not discriminate between bronchial carcinoma and mesothelioma) and compensation was awarded to victims.

The reference to the paper by WeIss [5] in 1953 is of interest as the first report of a death where two primary respiratory malignancies, bronchial carcinoma and pleural mesothelioma, were found in one asbestos worker.

They state that the report of WAGNER et al. [6] of 33 cases (a postscript to this paper refers to a total of 47 cases by the end of June 1960) put the association between the tumour and asbestos beyond reasonable doubt. Many would agree with McDonald and McDonald [1] on this point, but WAGNER et al. [6] seemed less certain. To quote them: "...the pathological evidence for associating these tumours with asbestos exposure is not conclusive. As previously stated, only in eight of the 33 cases has evidence of asbestos been demonstrated... In the remaining 25 cases we can only present circumstantial evidence of exposure to asbestos dust...If asbestos dust is a factor in the occurrence of these tumours, similar cases might have been expected from the neighbourhood of the Transvaal asbestos mines...".

Five years previously, BONSER et al. [7] analysed data collected by Stewart on a series of 72 asbestos worker postmortems in which asbestosis was present, and reported four peritoneal tumours and one and possibly two primary pleural tumours. Curiously, the term mesothelioma was not used in this paper, though Stewart did employ it in his records.

In a restrained manner MCDonaLD and MCDonaLD [1] refer to the hurtful accusations levelled against them arising out of their involvement in this field, when they write: "...investigators familiar with the disastrous experience of insulation workers in North America [naming no names]...regrettable conclusion was that the data from Quebec, Canada, [the authors' study] was wrong, or worse...". They add to it other hints of closed minds and a lack of generosity among their antagonists: "...no great difficulty was found in maintaining their disbelief [in the low carcinogenicity of chrysotile] ...less flattering reasons were not far below the surface". To present an even-handed historic account of events however, the reader needs to be informed of the ungentle measures employed by industry to counter and silence scientists who opposed their views. There is a wealth of historic material now available that the authors could have quoted to better inform the reader on the politics of asbestos history.

As for the scientific conclusions reached by the authors, readers may wish to compare them with the consensus expert opinion on the hazards arising from exposure to chrysotile asbestos in the International Programme of 
Chemical Safety Environmental Health Criteria document series published by The World Health Organization (WHO) [8]. This has been reviewed recently, but there is no reason to expect that they will recommend a relaxation of WHO public health policy [9].

\section{References}

1. McDonald JC, McDonald AD. The epidemiology of mesothelioma in histological context. Eur Respir $J$ 1996; 9: 1932-1934.

2. Gloyne SR. Two cases of squamous carcinoma of the lung occurring in asbestosis. Tubercle 1935; 17: 5-10.

3. Cartier P. Abstract of discussion. In: Smith WE, eds. Survey of Some Current British and European Studies of Occupational Tumour Problems. Arch Industr Hyg Med 1952; 5: 242-263.

4. Wedler HW. Über den Lungenkrebs bei Asbestose. Dtsch Arch Klin Med 1943; 191: 189-209.
5. Weiss A. Pleurakrebs bei Lungenasbestose, in vivo morphologisch gesichert. Medizinische 1953; 3: 93-94.

6. Wagner JC, Sleggs CA, Marchand P. Diffuse pleural mesothelioma and asbestos exposure in the North Western Cape Province. Br J Industr Med 1960; 17: 260271.

7. Bonser GM, Faulds JS, Stewart MJ. Occupational cancer of the urinary bladder in dyestuffs operatives and of the lung in asbestos textile workers and iron-ore miners. Am J Clin Path 1955; 23: 126-134.

8. Environmental Health Criteria 53. Asbestos and other natural mineral fibres. Geneva, WHO, 1986.

9. WHO Press Office. Chrysotile asbestos evaluated by health experts Press Release WHO/51/Rev. 1. 9th September 1996.

\section{Greenberg}

74 North End Road, London NW11 7SY, UK.

\section{REPLY}

\section{From the authors:}

We are grateful to Dr Greenberg for his comments on our historical review of the epidemiology of mesothelioma [1], and particularly for identifying inaccuracies in our account of the early recognition of the link with asbestos. The paper published by GLOYNE [2] in 1935, was indeed concerned with lung cancer and not with mesothelioma, although, at that time, the distinction was not always clear. For example, it is of passing interest that Gloyne, in an earlier paper [3], while reviewing his extensive observations on asbestosis, included the statement: "There has also been one case of squamous carcinoma of the pleura. There is no evidence at the moment (our italics) that this was in any way related to the asbestosis". We also agree that it is difficult to know now what the opinion of CARTIER [4] really was on the aetiology of the "two such rare cancers in a small series of only eight cases", especially as we are not able to document it. If anything, it seems more likely from the reported discussion that this may have been the opinion of the chairman, W.E. Smith, rather than of Cartier.

We are sure that Dr Greenberg would not expect us to agree entirely with his further comments: the subject has been controversial enough without making it more so. Our paper was intended to present an account of the scientific evidence as it developed over the last $40 \mathrm{yrs}$ and to consider the reasons why progress was and still is seriously retarded by bitter and unscrupulous controversy. The fact that industry, labour, journalists, lawyers and others with vested interests, undoubtedly contributed their share is not remarkable. That members of the so-called scientific community stoked the fires is less usual and surely more reprehensible.

\section{References}

1. McDonald JC, McDonald AD. The epidemiology of mesothelioma in historical context. Eur Respir J 1996; 9: 1932-1942.

2. Gloyne SR. Two cases of squamous carcinoma of the lung occurring in asbestosis. Tubercle 1935; 17: 5-10.

3. Gloyne SR. The morbid anatomy and histology of asbestosis. Tubercle 1933; 14: 550-558.

4. Cartier P. Abstract of discussion. In: Smith WE, eds. Survey of Some Current British and European Studies of Occupational Tumour Problems. Arch Industr Hyg Med 1952; 5: 242-263.

\section{J.C. McDonald}

Imperial College School of Medicine at the National Heart and Lung Institute, Dovehouse Street, London SW3 6LY, UK. 